\title{
correspondence
}

\section{Allergic reactions to laboratory animals}

SIR-There is a growing concern about allergic reactions in laboratory workers who handle animals but little factual evidence is available. The British Society for Allergy and Clinical Immunology appointed a working party to investigate this subject and here we report preliminary findings, which give some idea of the size of the problem.

We used a questionnaire in two laboratories, one industrial and the other non-industrial, but the results were closely similar, so here we amalgamate them. 474 individuals were questioned. Salient points were, that of this population,

- $23 \%$ had had one or more symptoms occurring repeatedly within 12 hours of animal contact

- $9 \%$ had had chest, 17\% nasal, $10 \%$ eye and $11 \%$ skin symptoms

- $4 \%$ had had to stop working with animals

- after two years of exposure the incidence of allergy did not increase significantly with further exposure

- a family history of allergy was present in $22 \%$ of those who reported symptoms, $19 \%$ of those who did not. This surprisingly small difference calls into question the usefulness of a preemployment family-history screen, and is at variance with results from a recent survey in the USA (Lutsky I. I., and Neuman, I., Annals Allergy, 31, 201 (1975)).

We regard the figure of $23 \%$ as disturbingly high, higher than those reported recently from the USA (two surveys gave $15 \%$ and $11 \%$ ), and we are starting a much larger survey to investigate factors which may alter the incidence of allergic reactions in exposed populations.

Yours faithfully,

GeOFFrey TAYLOR (CHMN.)

G. E. Davies (SEC.)

R. E. C. Altounyan

H. Morrow Brown

A. W. FrankLand

J. MORRISON SMITH

R. WINCH

British Society for Allergy and Clinical Immunology,

Working Party on sensitivity to laboratory animals,

c/o Immunology Laboratory,

University of Manchester,

Manchester, UK

\section{Volume publishing}

SIR,-I write to draw attention to, to underline, and to generalise from, the exquisite review (March 4, page 82) of the Handbook of Perception, which I have not seen. Dr John Mollon lambasts non-editing, a feature not confined to the publishers of the Handbook, and unfortunately rife in the field of science publishing

Progressive specialisation and illiteracy make it clearly more and more difficult for any one author to cover a field in depth: hence the mushrooming of Editored volumes during the last decade or two. A publisher approaches a Name, offers a percentage out of all proportion to the services rendered (which frequently consist in no more than drawing up a list of contributors and acting as a relay station for the receipt of typescripts), and informs the Inland Revenue at the appropriate time.

The contributors are also offered a percentage out of all proportion to the services rendered: I know of a case where the typist was paid more than the author. They are often up-andcoming youngsters who will not heed the warnings of us older hacks. I always point out to younger colleagues that fixed payments are to be avoided like the plague especially if they are made after publication: inflation eats into the terms but the selling price of the book can protect the publisher and editor. I also stress the naïveté of the notion that they will derive any kudos: later references are almost invariably made to the Editor-so-called, with the author's name sunk in Lethe. The crowning insult occurs when a generous publisher sends along 25 reprints, and so ensures a reduction in sales.

It seems to me that there is a case for an agreed code of good conduct to protect the interests of (young) authors who probably cannot afford the luxury of membership of authors' protective associations - which can, in any case, do little more than offer advice. Moreover, if Editors started spelling their designation with a lower-case $e$, the interests of authors might begin to be guarded, and one of the last relics of child labour expunged from society. Yours faithfully,

$$
\text { R. A. Wrale }
$$

Department of Visual Science, Institute of Ophthalmology, University of London,

London, UK

\section{Alternative refrigerants}

SIR-The letter from Birks and Leck, (Correspondence, March 4, page 8) avers that while we can do without aerosol cans, our civilization cannot function without refrigerators. It is then suggested that, if we do not choose to give up refrigerators, we may have to continue tolerating atmospheric pollution by chlorofluorocarbons, even if we ban aerosol cans.

The implication that we are faced with such an awkward choice is not, I think, correct. It is true that we can prevent release of chlorofluorocarbons into the atmosphere by aerosol cans in only one way: ban aerosol cans. It is an essential part of their operation to release the gas they contain.

This is not true of refrigerators, which normally release their refrigerant gas only when junked. This release could be almost completely prevented by

- a law making it an offence carrying a heavy penalty to junk a refrigerator without first having a suitable public or private (licensed) agency remove the refrigerant, or

- much better, requiring a meaningfully large deposit to be left when a refrigerator is purchased and rebating that sum, plus inflation related interest, only upon presentation of proof that the refrigerant has been duly recovered by the designated agency.

We can, in short, keep refrigerators and save our atmosphere, even if it becomes necessary to discontinue using aerosol cans.

$$
\begin{aligned}
& \text { Yours faithfully, } \\
& \text { F. A. Cotron }
\end{aligned}
$$

Department of Chemistry,

Texas $A$ \& $M$ University,

College of Science,

Texas 77843

\section{The pace of life}

SIR-Hermits can communicate with everyone in their community by standing still (February 19, page 557 and March 18, page 188). But what about pedestrians in downtown Tokyo (population in excess of $10^{7}$ )? Can anyone confirm that they walk at almost $2 \mathrm{~m} \mathrm{~s}^{-1}$ ?

$$
\text { Yours faithfully, }
$$

$$
\text { RALPH A. LEWIN }
$$

Scripps Institution,

La Jolla,

California 92037 